\title{
Gastro-intestinal dysfunctions in Parkinson's disease (Review)
}

\author{
IRINA-FLORINA IVAN $^{1 *}$, VALENTINA-LAURA IRINCU ${ }^{1 *}$, STEFANIA DIACONU $^{2 *}$, \\ OANA FALUP-PECURARIU ${ }^{2}$, BOGDAN CIOPLEIAȘ ${ }^{1}$ and CRISTIAN FALUP-PECURARIU ${ }^{1,2}$ \\ ${ }^{1}$ Department of Neurology, County Emergency Clinic Hospital, 500365 Brașov; \\ ${ }^{2}$ Faculty of Medicine, Transilvania University, 500036 Brașov, Romania
}

Received May 18, 2021; Accepted June 16, 2021

DOI: $10.3892 /$ etm.2021.10517

\begin{abstract}
In patients with Parkinson's disease (PD), gastrointestinal dysfunction occurs from the early stages of the disease and even in the pre-motor phase. This condition can include the entire digestive tract, with symptoms ranging from delays in gastric emptying to dysphagia, constipation and even malnutrition. Excess saliva accumulates in the mouth due to the low frequency of swallowing. Dysphagia develops in about $50 \%$ of patients and may be a reflection of both central nervous system and enteric nervous system disorder. Gastroparesis can cause a variety of symptoms, including nausea, and also may be responsible for some of the motor fluctuations observed with levodopa therapy. Intestinal dysfunction in PD may be the result of both delayed colon transit and impaired anorectal muscle coordination. In addition, recent studies have demonstrated the role of Helicobacter pylori infection in the pathogenesis of diseases but also the occurrence of motor fluctuations by affecting the absorption of anti-parkinsonian medication. In this review, the main gastrointestinal dysfunctions associated with PD are presented.
\end{abstract}

\section{Contents}

1. Introduction

2. Swallowing disorders

3. Gastric dysfunction

4. Helicobacter pylori infection

5. Constipation

6. Malnutrition

7. Conclusions

Correspondence to: Dr Oana Falup-Pecurariu, Faculty of Medicine, Transilvania University, 56 Nicolae Bălcescu Street, 500036 Brașov, Romania

E-mail: oanafp@yahoo.co.uk

${ }^{*}$ Contributed equally

Key words: gastrointestinal dysfunction, drooling, dysphagia, gastroparesis, constipation, Parkinson's disease

\section{Introduction}

Patients with Parkinson's disease (PD) may present dysfunctions of the gastrointestinal system from the early stages of the disease; in some cases even before the occurrence of the motor symptoms. The gastrointestinal system could be affected at all levels and this is known to reduce patient quality of life and increase mortality (1).

The clinical manifestations of gastrointestinal dysfunctions in PD include drooling, dysphagia, gastric dysfunction (delayed emptying and gastroparesis, Helicobacter pylori (HP) infection), constipation, dyssynergic defecation and malnutrition. One important aspect of gut dysfunction consists in its contribution to the clinical fluctuations in PD. Moreover, PD patients seem to have a particular susceptibility to HP infection (2). Dysphagia, delayed emptying and gastroparesis induce inadequate absorption of oral anti-PD medications, that could worsen motor impairment. Aspiration pneumonia, the deadliest complication of swallowing deficits, is a common cause of death in patients with PD (3). Gastro-intestinal symptoms, such as constipation, dyssynergic defecation and malnutrition present with high prevalence in these patients (4).

Among non-motor symptoms, the gastrointestinal symptoms of PD have high prevalence worldwide, as it has been shown in validation studies of the non-motor symptoms scale (5) as well as in studies investigating autonomic dysfunctions (6). The occurrence of gastrointestinal symptoms varies, depending on several parameters, such as age, sex, severity of PD and other comorbidities. Regarding sex differences, women are more affected by constipation than men; drooling being more prevalent in men (7).

\section{Swallowing disorders}

Dysphagia is a symptom that occurs frequently in patients with PD and its severity corresponds with the severity of the disease (8). It occurs with a prevalence of between 9 and $82 \%$ in patients with PD (1,9-12). This symptom is more commonly associated with male sex, longer duration of disease, advanced age, depression, dementia and more severe motor symptoms $(13,14)$.

The variability in the estimated prevalence of dysphagia occurs due to the lack of well-established diagnostic criteria. This finding may be a reflection of the fact that each clinician uses different screening questionnaires and some of them 
use objective methods of measuring dysphagia, depending on preferences and possibilities (1).

Dysphagia in PD is mainly caused by the dysfunction of swallowing mechanisms in the oral, pharyngeal and esophageal cavities. Bradykinesia and incoordination also play a major role in the occurrence of dysphagia (1). It is worth mentioning that dysfunctions of the cortical area, central cholinergic pathways $(15,16)$, as well as of the peripheral nerves are involved in the development of swallowing impairments (13).

Another common symptom found in PD patients caused by dysfunction of the swallowing mechanisms is drooling. The prevalence of this symptom varies from 10 to $84 \%$ in PD patients, being more common in advanced PD stages $(1,17)$. This symptom, defined by saliva flowing outside of a patient's mouth unintentionally, can have two different mechanisms of occurrence: Either through overproduction of saliva or through impaired salivary clearance. In PD patients, the causative mechanism seems to be the inefficiency of the process of swallowing saliva rather than the overproduction of saliva, since some studies mention cases of decreased salivary production in $\operatorname{PD}(8,16)$.

On the other hand, drooling can also be correlated with the severity of PD motor symptoms. Unintentional mouth opening that occurs with hypomimia in these patients, dysarthria, dysphagia and abnormal head position lead to drooling $(17,18)$. These observations are reinforced by the fact that the intensity of drooling is higher during the off periods, thus supporting the theory that swallowing difficulties are the mechanism by which this symptom occurs, and not excessive saliva production (1).

The negative effects of drooling are both of a social nature and of pathological importance. Therefore, patients may feel ashamed, may have poor oral hygiene, bad breath, excessive growth of oral microbial flora, all leading to a diminished quality of life. In addition, the difficulties that appear during feeding and speech expose PD patients to an increased risk of aspiration pneumonia (present in $15-56 \%$ of PD patients), either through silent laryngeal penetration of food or through silent aspiration (19).

\section{Gastric dysfunction}

A common motility disorder that occurs in PD is impaired gastric emptying, which can be connected with various symptoms such as anorexia, early satiety, nausea, vomiting, or bloating. These symptoms can have serious consequences such as weight loss, malnutrition and dehydration (20). Gastroparesis has an increasing prevalence, although it is not always symptomatic, being present in $70-100 \%$ of PD patients (21); this symptom occurs regardless of the disease stage (both in the beginning and end stages of PD), being more strongly associated with solid meals (22). Impairment of gastric emptying is associated with the severity of motor dysfunction, but not with age or sex (23). It should be noted that levodopa medication is predominantly absorbed in the small intestine, so that gastroparesis may lead to a decreased medication effect (1). There is an important correlation between gastric emptying and levodopa pharmacokinetics $(10,24)$. Moreover, there are studies that suggest that levodopa itself has an effect on intestinal motility, resulting in delayed gastric emptying (21).

\section{Helicobacter pylori infection}

Helicobacter pylori (HP) may be involved in the pathogenesis of PD due to the chronic inflammatory response triggered by the infection, so it may play a part in the onset, evolution and outcome of PD, creating different views on its role in PD (1).

On the other hand, due to the interference in the levodopa absorption process, HP directly contributes to motor fluctuations, with concrete evidence in this regard $(25,26)$.

There are some studies suggesting that the pharmacokinetics of levodopa is identical for both HP and non-infected patients $(26,27)$. Due to the interference that it may have on levodopa absorption, the eradication of HP could diminish the motor fluctuations, prevent the deterioration of general health and improve the clinical status of PD patients (28).

\section{Constipation}

Constipation is probably the most common gastrointestinal manifestation of PD and is reported in $80-90 \%$ of cases $(1,29)$. This symptom can precede the onset of the disease even by 20 years $(30,31)$ and it appears long before the onset of the motor symptoms; thereby it is one of the first gastrointestinal manifestations of PD $(32,33)$. Furthermore, there is an increased prevalence of future PD patients in individuals with constipation $(31,32)$. Over time, attempts have been made to identify the mechanisms behind this symptom, with several theories intertwined. Involved in the onset of constipation is the prolonged transit time of the colon $(34,35)$. In addition to slow transit constipation, PD patients may also experience symptoms related to impaired neurological control of the rectum and anus, which may cause straining and incomplete emptying. This is also known as outlet obstruction or dyssynergic defecation, and can occur when the rectal sphincter fails to relax. In some studies, this phenomena is considered dystonia $(32,34,36)$.

On the other hand, the anti-parkinsonian treatment (for instance dopamine agonists and anticholinergics) may also induce constipation. However, it should be noted that delayed colonic transit occurs in both naive PD patients as well as in those on drug treatment (35). The symptoms of constipation are various, starting from rare stools, unsuccessful defecation attempts, incomplete rectal emptying sensation, evolving to systemic effects such as decreased appetite, reduced drug absorption, reabsorption of intestinal toxins, dysbiosis and malabsorption of nutrients $(37,38)$. Constipation may lead to the delay or failure of absorption of levodopa, contributing to the pathogenesis of motor fluctuations. These claims are supported by the improvement of extrapyramidal symptoms with the effective treatment of constipation in patients with PD (39).

Conversely, some authors have described numerous cases of fecal incontinence in patients with PD (35).

\section{Malnutrition}

PD is generally associated with weight changes, whether it is weight gain or loss, leading to a decreased quality of life. Malnutrition in PD occurs with a prevalence ranging between $0-24 \%$, and the risk of a PD patient developing malnutrition 
in the future is estimated between 3-60\% (40-42). According to several studies, malnutrition is associated with increased severity and duration of disease, aging, female sex, loss of appetite, psychiatric symptoms such as anxiety or depression, fatigue and loss of taste or smell $(43,44)$. In addition, decreased body mass index (BMI) in the first 6 months after the diagnosis of PD is associated with a higher risk of dementia (16).

Malnutrition occurs primarily as a result of reduced food intake due to decreased appetite, or due to gastrointestinal dysfunction (such as dysphagia) (40). Another cause is dyskinesia, which contributes to malnutrition by increasing energy consumption (44); additionally, decreased BMI is associated with increased risk of dyskinesia, thus creating a vicious circle $(44,45)$. Interestingly, an increased dose of levodopa is also associated with a higher risk of malnutrition (46).

Micronutrient deficiencies are common in PD, particularly vitamin D deficiency/insufficiency $(16,36,47)$, most likely these events being related to immobility, malnutrition and sunlight deprivation. In addition, patients with PD may have osteoporosis. Levodopa treatment can cause folic acid and vitamin B12 deficiency, leading to hyperhomocysteinemia, which may also contribute to osteoporosis (16).

Another problem that PD patients must face is weight gain. One of the causes is dopamine agonist treatment (compulsive eating and weight gain) and neurosurgical procedures, such as deep-brain stimulation of the subthalamic nucleus (48-51).

In the early stages of PD, weight gain occurs due to decreased oxidation of lipids and proteins and high levels of ghrelin (secreted by the stomach and causing hunger) and neuropeptide $\mathrm{Y}$, but as the disease progresses patients lose weight due to high levels of leptin (secreted by adipose tissue and which has an anorexigenic effect) decreased ghrelin levels and sarcopenia (52).

Early therapeutic interventions are needed in the case of nutritional disorders in PD. The patients should be informed about physical exercises, lifestyle changes, dietary supplementation and adverse effects of anti-parkinsonian drugs.

\section{Conclusions}

In PD, the gastrointestinal tract is affected early and extensively. In addition, gastrointestinal dysfunctions can affect the pharmacodynamics of anti-parkinsonian drugs, causing a worsening of the motor function. Therefore, gastrointestinal dysfunction in PD should be promptly identified and treated. Yet, for this to be possible, clinicians must pay attention to these symptoms during the follow-up examination of the PD patient.

\section{Acknowledgements}

Not applicable.

\section{Funding}

This present review article was supported by Transilvania University from Braşov, Romania under contract no. 8023/14.07.2017 (CFP, SD, OFP).

\section{Availability of data and materials}

All information provided in this review is documented by relevant references.

\section{Authors' contributions}

IFI made substantial contributions to the conception of the manuscript and the drafting of the manuscript. VLI made substantial contributions to the conception of the manuscript and the drafting of the manuscript. SD made substantial contributions to the conception of the manuscript, and revised the manuscript for important intellectual content. OFP made substantial contributions to the conception of the manuscript, and revised it critically for important intellectual content; $\mathrm{BC}$ made substantial contributions to the conception of the manuscript and revised it critically for important intellectual content. CFP made substantial contributions to the conception of the manuscript, and drafted the manuscript. All authors contributed to the literature review process, read and approved the final manuscript. All authors are in agreement to be accountable for all aspects of the work in ensuring that questions related to the accuracy or integrity of any part of the work are appropriately investigated and resolved.

\section{Ethics approval and consent to participate}

Not applicable.

\section{Patient consent for publication}

Not applicable.

\section{Competing interests}

The authors declare that they have no competing interests.

\section{Authors' information}

ORCID IDs: Irina-Florina Ivan: 0000-0001-7146-2323; Valentina-Laura Irincu: 0000-0003-4755-5655; Ştefania Diaconu: 0000-0002-0251-4043; Oana Falup-Pecurariu: 0000-0003-1972-6859;BogdanCiopleiaș:0000-0002-3680-7565 and Cristian Falup-Pecurariu: 0000-0002-7394-7161.

\section{References}

1. Fasano A, Visanji NP, Liu LWC, Lang AE and Pfeiffer RF: Gastrointestinal dysfunction in Parkinson's disease. Lancet Neurol 14: 625-639, 2015

2. Dardiotis E, Tsouris Z, Mentis AA, Siokas V, Michalopoulou A, Sokratous M, Dastamani M, Bogdanos DP, Deretzi G and Kountouras J: H. pylori and Parkinson's disease: Meta-analyses including clinical severity. Clin Neurol Neurosurg 175: 16-24, 2018.

3. Iwasaki S, Narabayashi Y, Hamaguchi K, Iwasaki A and Takakusagi M: Cause of death among patients with Parkinson's disease: A rare mortality due to cerebral haemorrhage. J Neurol 237: 77-79, 1990.

4. Palma JA and Kaufmann H: Treatment of autonomic dysfunction in Parkinson disease and other synucleinopathies. Mov Disord 33: 372-390, 2018. 
5. van Wamelen DJ, Martinez-Martin P, Weintraub D, Schrag A, Antonini A, Falup-Pecurariu C, Odin P and Ray Chaudhuri K; International Parkinson and Movement Disorder Society Parkinson's Disease Non-Motor Study Group: The non-motor symptoms scale in Parkinson's disease: Validation and use. Acta Neurol Scand 143: 3-12, 2021.

6. Bostantjopoulou S, Katsarou Z, Danglis I, Karakasis H, Milioni D and Falup-Pecurariu C: Self-reported autonomic symptoms in Parkinson's disease: Properties of the SCOPA-AUT scale. Hippokratia 20: 115-120, 2016.

7. Martinez-Martin P, Falup Pecurariu C, Odin P, van Hilten JJ, Antonini A, Rojo-Abuin JM, Borges V, Trenkwalder C, Aarsland D, Brooks DJ, et al: Gender-related differences in the burden of non-motor symptoms in Parkinson's disease. J Neurol 259: 1639-1647, 2012.

8. Lin CW, Chang YC, Chen WS, Chang K, Chang HY and Wang TG: Prolonged swallowing time in dysphagic Parkinsonism patients with aspiration pneumonia. Arch Phys Med Rehabil 93: 2080-2084, 2012.

9. Kalf JG, de Swart BJM, Bloem BR and Munneke M: Prevalence of oropharyngeal dysphagia in Parkinson's disease: A meta-analysis. Park Relat Disord 18: 311-315, 2012.

10. Müller J, Wenning GK, Verny M, McKee A, Chaudhuri KR, Jellinger K, Poewe W and Litvan I: Progression of dysarthria and dysphagia in postmortem-confirmed parkinsonian disorders. Arch Neurol 58: 259-264, 2001.

11. O'Sullivan SS, Massey LA, Williams DR, Silveira-Moriyama L, Kempster PA, Holton JL, Revesz T and Lees AJ: Clinical outcomes of progressive supranuclear palsy and multiple system atrophy. Brain 131: 1362-1372, 2008.

12. Nicaretta DH, de Rosso AL, Maliska C and Costa MM: Scintigraphic analysis of the parotid glands in patients with sialorrhea and Parkinson's disease. Park Relat Disord 14: 338-341, 2008.

13. Cereda E, Cilia R, Klersy C, Canesi M, Zecchinelli AL, Mariani CB, Tesei S, Sacilotto G, Meucci N, Zini M, et al: Swallowing disturbances in Parkinson's disease: A multivariate analysis of contributing factors. Park Relat Disord 20: 1382-1387, 2014.

14. Han M, Ohnishi H, Nonaka M, Yamauchi R, Hozuki T, Hayashi T, Saitoh M, Hisahara S, Imai T, Shimohama S and Mori M Relationship between dysphagia and depressive states in patients with Parkinson's disease. Park Relat Disord 17: 437-439, 2011.

15. Kikuchi A, Baba T, Hasegawa T, Kobayashi M, Sugeno N, Konno M, Miura E, Hosokai Y, Ishioka T, Nishio Y, et al Hypometabolism in the supplementary and anterior cingulate cortices is related to dysphagia in Parkinson's disease: A cross-sectional and 3-year longitudinal cohort study. BMJ Open 3: e002249, 2013.

16. Mukherjee A, Biswas A and Das SK: Gut dysfunction in Parkinson's disease. World J Gastroenterol 22: 5742-5752, 2016.

17. Srivanitchapoom P, Pandey $S$ and Hallett $M$ : Drooling in Parkinson's disease: A review. Park Relat Disord 20: 1109-1118, 2014.

18. Kalf JG, De Swart BJM, Borm GF, Bloem BR and Munneke M: Prevalence and definition of drooling in Parkinson's disease: A systematic review. J Neurol 256: 1391-1396, 2009.

19. Kalf J, de Swart B, Bloem BR and Munneke M: Development and evaluation of a severity scale (DSFS-P) and questionnaire for drooling in Parkinson's disease (ROMP-saliva). Parkinsonism Relat Disord 13 (Suppl): S47, 2007.

20. Rozenberg A, Gurevich T, Giladi N and Korczyn AD: Gastric dysfunction in Parkinson's disease. In: Parkinson's disease and Nonmotor Dysfunction. Pfeiffer RF and Bodis-Wollner I (eds). Humana Press, New York, NY, pp145-154, 2013.

21. Heetun ZS and Quigley EM: Gastroparesis and Parkinson's disease: A systematic review. Park Relat Disord 18: 433-440, 2012.

22. Goetze O, Nikodem AB, Wiezcorek J, Banasch M, Przuntek H, Mueller T, Schmidt WE and Woitalla D: Predictors of gastric emptying in Parkinson's disease. Neurogastroenterol Motil 18 : 369-375, 2006

23. Pfeiffer R: Gastrointestinal and swallowing disturbances in Parkinson's disease. In: Parkinson's Disease: Non-Motor and Non-dopaminergic Features. Olanow CW, Stocchi F and Lang AE (eds). Wiley-Blackwell, Oxford, pp257-273, 2011.

24. Marrinan S, Emmanuel AV and Burn DJ: Delayed gastric emptying in Parkinson's disease. Mov Disord 29: 23-32, 2014.
25. Rahne KE, Tagesson C and Nyholm D: Motor fluctuations and Helicobacter pylori in Parkinson's disease. J Neurol 260: 2974-2980, 2013

26. Narożańska E, Białecka M, Adamiak-Giera U, Gawrońska-Szklarz B, Sołtan W, Schinwelski M, Robowski P, Madaliński MH and Sławek J: Pharmacokinetics of levodopa in patients with Parkinson disease and motor fluctuations depending on the presence of Helicobacter pylori infection. Clin Neuropharmacol 37: 96-99, 2014.

27. Pierantozzi M, Pietroiusti A, Brusa L, Galati S, Stefani A, Lunardi G, Fedele E, Sancesario G, Bernardi G, Bergamaschi A, et al: Helicobacter pylori eradication and L-dopa absorption in patients with PD and motor fluctuations. Neurology 66: 1824-1829, 2006.

28. Lee WY, Yoon WT, Shin HY, Jeon SH and Rhee PL: Helicobacter pylori infection and motor fluctuations in patients with Parkinson's disease. Mov Disord 23: 1696-1700, 2008.

29. Maeda T, Shimo Y, Chiu SW, Yamaguchi T, Kashihara K, Tsuboi Y, Nomoto M, Hattori N, Watanabe H and Saiki H; J-FIRST group: Clinical manifestations of nonmotor symptoms in 1021 Japanese Parkinson's disease patients from 35 medical centers. Park Relat Disord 38: 54-60, 2017.

30. Savica R, Carlin JM, Grossardt BR, Bower JH, Ahlskog JE, Maraganore DM, Bharucha AE and Rocca WA: Medical records documentation of constipation preceding Parkinson disease: A case-control study. Neurology 73: 1752-1758, 2009.

31. Ueki A and Otsuka M: Life style risks of Parkinson's disease: Association between decreased water intake and constipation. J Neurol 251 (Suppl 7): vII18-vII23, 2004.

32. Bassotti G, Maggio D, Battaglia E, Giulietti O, Spinozzi F, Reboldi G, Serra AM, Emanuelli G and Chiarioni G: Manometric investigation of anorectal function in early and late stage Parkinson's disease. J Neurol Neurosurg Psychiatry 68: 768-770, 2000.

33. Lesser GT: Frequency of bowel movements and future risk of Parkinson's disease. Neurology 58: 838-839, 2002.

34. Lin CH, Lin JW, Liu YC, Chang $\mathrm{CH}$ and Wu RM: Risk of Parkinson's disease following severe constipation: A nationwide population-based cohort study. Park Relat Disord 20: 1371-1375, 2014.

35. Jost WH: Gastrointestinal dysfunction in Parkinson's disease. J Neurol Sci 289: 69-73, 2010.

36. Mathers SE, Kempster PA, Swash M and Lees AJ: Constipation and paradoxical puborectalis contraction in anismus and Parkinson's disease: A dystonic phenomenon? J Neurol Neurosurg Psychiatry 51: 1503-1507, 1988.

37. Krogh $\mathrm{K}$ and Christensen P: Neurogenic colorectal and pelvic floor dysfunction. Best Pract Res Clin Gastroenterol 23: 531-543, 2009.

38. Kwon KY, Jo KD, Lee MK, Oh M, Kim EN, Park J, Kim JS, Youn J, Oh E, Kim HT, et al: Low serum vitamin D levels may contribute to gastric dysmotility in de novo Parkinson's disease. Neurodegener Dis 16: 199-205, 2016.

39. Stocchi $\mathrm{F}$ and Torti M: Constipation in Parkinson's disease. Int Rev Neurobiol 134: 811-826, 2017.

40. Sheard JM, Ash S, Mellick GD, Silburn PA and Kerr GK: Malnutrition in a sample of community-dwelling people with Parkinson's disease. PLoS One 8: e53290, 2013.

41. Wang G, Wan Y, Cheng Q, Xiao Q, Wang Y, Zhang J, Ma JF, Wang XJ, Zhou HY and Chen SD: Malnutrition and associated factors in Chinese patients with Parkinson's disease: Results from a pilot investigation. Park Relat Disord 16: 119-123, 2010.

42. Mischley LK: Nutrition and nonmotor symptoms of Parkinson's disease. Int Rev Neurobiol 134: 1143-1161, 2017.

43. Damian A, Adler CH, Hentz JG, Shill HA, Caviness JN, Sabbagh MN, Evidente VG, Beach TG and Driver-Dunckley E: Autonomic function, as self-reported on the SCOPA-autonomic questionnaire, is normal in essential tremor but not in Parkinson's disease. Park Relat Disord 18: 1089-1093, 2012.

44. Barichella M, Cereda E and Pezzoli G: Major nutritional issues in the management of Parkinson's disease. Mov Disord 24: 1881-1892, 2009.

45. Kistner A, Lhommée E and Krack P: Mechanisms of body weight fluctuations in Parkinson's disease. Front Neurol 5: 84, 2014.

46. Laudisio A, Vetrano DL, Meloni E, Ricciardi D, Franceschi F, Bentivoglio AR, Bernabei $R$ and Zuccalà $G$ : Dopaminergic agents and nutritional status in Parkinson's disease. Mov Disord 29: 1543-1547, 2014. 
47. Lv Z, Qi H, Wang L, Fan X, Han F, Wang H and Bi S: Vitamin D status and Parkinson's disease: A systematic review and meta-analysis. Neurol Sci 35: 1723-1730, 2014.

48. Morales-Briceño H,Cervantes-Arriaga A, Rodríguez-Violante M, Calleja-Castillo $\mathrm{J}$ and Corona T: Overweight is more prevalent in patients with Parkinson's disease. Arq Neuropsiquiatr 70: 843-846, 2012.

49. Nirenberg MJ and Waters C: Compulsive eating and weight gain related to dopamine agonist use. Mov Disord 21: 524-529, 2006.
50. Strowd RE, Herco M, Passmore-Griffin L, Avery B, Haq I, Tatter SB, Tate J and Siddiqui MS: Association between subthalamic nucleus deep brain stimulation and weight gain: Results of a case-control study. Clin Neurol Neurosurg 140: 38-42, 2016.

51. Vikdahl M, Carlsson M, Linder J, Forsgren L and Håglin L: Weight gain and increased central obesity in the early phase of Parkinson's disease. Clin Nutr 33: 1132-1139, 2014.

52. Kistner A, Lhommée E and Krack P: Mechanisms of body weight fluctuations in Parkinson's disease. Front Neurol 5: 84, 2014. 